\title{
Antes do rio, porteiras e cadeados: apropriações da terra e disputas por usos do médio rio Ívaí-PR
}

Before the river, gates and locks: land appropriations and disputes over the use of middle Rio IvaíPR

Antes del río, puertas y esclusas: apropiaciones de tierras y disputas por el uso del Río Ívaí-PR medio

\section{Resumo}

Objetivo: analisar no médio Ivaí-PR, algumas formas de apropriação humana da terra e do rio. Metodologia: discussão do referencial teórico, da legislação, dados do médio Ivaí e trabalho de campo, como estratégia para demonstrar os estudos da história ambiental da área. Resultados e discussão: Para evidenciar tais formas de apropriação, destacou-se os pescadores e os proprietários de terras lindeiras (chacareiros, agricultores e pecuaristas). Todos originários do processo de ocupação privada das terras ocorrido na segunda metade do século XX. Considerações finais: evidenciouse que há um descompasso lacunar entre as configurações e práticas sociais de apropriação do rio e das terras e a implantação dos instrumentos de gestão dos recursos hídricos, conforme preconiza a legislação.

Palavras-chave: Rio Ivaí; História ambiental; Território em disputa.

\begin{abstract}
Objective: to analyze, in the middle of Ivaí-PR, some forms of human appropriation of land and river. Methodology: discussion of the theoretical framework, legislation, data from the Ivaí medium and fieldwork, as a strategy to demonstrate the studies of environmental history in the area. Results and discussion: To highlight such forms of appropriation, fishermen and owners of neighboring lands (chacareiros, farmers and ranchers) were highlighted. All originated from the process of private occupation of land that took place in the second half of the 21 th century. Final considerations: it was evident that there is a gap between the configurations and social practices of appropriation of the river and lands and the implementation of water resources management instruments, as recommended by legislation.
\end{abstract}

Keywords: River Ivaí; Environmental history; Disputed territory.

\section{Resumen}

Objetivo: analizar algunas formas de apropiación humana de tierras y ríos en medio de Ivaí-PR. Metodología: discusión del marco teórico, legislación, datos del medio Ivaí y trabajo de campo, como estrategia para demostrar los estudios de historia ambiental en la zona. Resultados y discusión: Para resaltar tales formas de apropiación, se destacaron pescadores y propietarios de tierras vecinas (chacareiros, agricultores y ganaderos). Todo se originó en el proceso de ocupación privada de tierras que tuvo lugar en la segunda mitad del siglo XX. Consideraciones finales: se evidenció que existe una brecha entre las configuraciones y prácticas sociales de apropiación del río y las tierras y la implementación de los instrumentos de gestión de los recursos hídricos, tal como lo recomienda la legislación.

Palabras clave: Río Ivaí; Historia ambiental; Territorio disputado.

\section{Introdução}

A história ambiental é um campo historiográfico que considera a natureza como um "agente ativo na história" (Ferri,

2017). Uma escrita que se constrói e ganha espaço no século XX, especialmente a partir da década de 1970, com as pesquisas 
de Donald Worster nos EUA. Na década de 1990, a história ambiental é globalmente institucionalizada enquanto campo teórico e acadêmico. No contexto das décadas de 1990 e 2000, na América Latina, um coletivo de pesquisadores emerge, ao dialogar com a história ambiental norte-americana. Um diálogo que, ao mesmo tempo reconhece a história ambiental como um campo inovador, mas também faz a crítica por ela pensar a relação humana com a natureza como um processo destrutivo.

Geograficamente a pesquisa teve como objeto analisar a história ambiental do rio Ivaí. Um rio integralmente paranaense, que percorre por 798 km no sentido sudeste-noroeste. O território às suas margens compõe a Bacia Hidrográfica do Rio Ivaí, que cobre área total de $36.646,36 \mathrm{~km}^{2}$. Para tanto se analisou que no médio Ivaí, algumas formas de apropriação humana da terra e do rio.

Uma hipótese considerada foi que essa mesma lógica privada se transportou para o rio, neste estudo, compreendido como um território em disputa por usos diversos. Usos que, contrariando os atos regulatórios vigentes, insuficientes, tardios e/ou inexistentes, impactam a dinâmica do rio e transformam a paisagem.

\section{Metodologia}

O presente trabalho se pautou pela discussão teórica do conceito de história ambiental como forma de analisar e contextualizar a ocupação e apropriação do médio Rio Ivaí-PR.

Nas décadas de 1990 a 2010, a história ambiental viveu o desafio de romper com a perspectiva teórico conceitual hegemônica do mundo ocidental ancorada na "disjunção da natureza e da cultura" (Carvalho, 2010, p. 135) e, ainda conforme o autor, incorporar nos seus modelos de análise elementos que congreguem e reconheçam as diferentes configurações sociais, as quais se conflitam ao se postarem no coletivo e projetarem seus usos e interesses no biofísico, abstratamente chamado de natureza. Neste sentido, Porto-Gonçalves (2012, p. 27), registra o desenvolvimento de "importantes correntes teórico-políticas no campo ambiental", dentre elas: o "Ecologismo dos Pobres" (Alier, 1992); a "reapropriação social da natureza" (Leff, 2006); a "justiça ambiental" (Acselrad, 2002).

Segundo Schama (1996, p.23):

"Embora a história do ambiente seja uma das mais originais e instigantes que estão sendo escritas hoje, ela, inevitavelmente, expõe o mesmo quadro desanimador: terras tomadas, exploradas, exauridas; culturas tradicionais que sempre viveram numa relação de sagrada reverência com o solo e foram desalojadas pelo individualista displicente, pelo agressor capitalista."

A história ambiental foi o campo teórico conceitual de suporte, cuja trajetória de institucionalização foi apresentada de forma bastante generalizada, para destacar o desafio atual deste campo historiográfico de incorporar aos seus modelos de análise elementos que congreguem e reconheçam as diferentes configurações sociais, conforme apresentadas aqui, a fins de superar o modelo ocidental homogeneizante, que reforça a concepção e narrativa do homem destruidor numa eterna disjunção entre sociedade e natureza (Carvalho, 2010).

Utilizou-se ainda da legislação e dados sobre rio para fundamentar o processo de ocupação das margens do médio Ivaí. O trabalho de campo foi utilizado como suporte para os estudos no campo da história ambiental gerando imagens a fim de demonstrar as formas de apropriações e disputas presentes, refletidas na paisagem impactada por diferentes agentes: Para evidenciar tais formas de apropriação na área de estudo, destacou-se os pescadores e os proprietários de terras lindeiras (chacareiros, agricultores e pecuaristas). Todos originários do processo de ocupação privada das terras ocorrido na segunda metade do século XX. 


\section{Resultados e Discussão}

\subsection{A história ambiental do médio Ivaí-PR}

No Brasil, a história ambiental nos é apresentada por José Augusto Drummond (1991) e seus pressupostos teóricos e metodológicos analisados também por José Augusto Pádua (2010). A partir destes precursores, a história ambiental, conforme defende Pádua (2010. p.94) tem um crescimento acadêmico e incorpora a análise histórica do biofísico, às dimensões econômicas, culturais, sociais e políticas, com a "capacidade concreta para ampliar a análise histórica e trazer novas perspectivas para o estudo de antigos problemas historiográficos."

Drummond (2002) considera o Brasil como terreno fértil para os estudos de história ambiental e Pádua (2010, p.96) diz que não se pode fazer pesquisa de história ambiental com base somente na "abstração das teorias", mas que elas se dão "por meio de recorte geográficos e biofísicos concretos: uma região florestal, uma bacia hidrográfica, uma cidade, uma zona agrícola, etc.” E, dentre as cinco características metodológicos e analítica desenvolvida por Drummond (1991, p.184), está o “trabalho de campo". Para o autor, “o trabalho de campo serve para identificar as marcas deixadas na paisagem pelos diferentes usos humanos, marcas essas que nem sempre constam em documentos escritos.” Inicialmente, foram estas bases teóricas e metodológicas que ampararam a delimitação geográfica deste trabalho, o rio Ivaí, e a pesquisa de campo como principal metodologia.

Isto posto, é um desafio aqui e no doutorado em construção, apropriar-se da Bacia Hidrográfica do Rio Ivaí, a qual reúne distintos grupos sociais, como uma unidade de análise a partir dos preceitos da história ambiental. Tem-se, portanto, um conjunto de diversidade ecológica e social, a qual se pretende analisar, na perspectiva de identificar as demandas que emergiram no rio Ivaí após a década de 1970 e as particularidades que podem estar influenciando as relações dos humanos com a natureza.

Conforme Porto e Porto (2008, p.43), o conceito de Bacia Hidrográfica remonta às décadas de 1920 e 1930 nos EUA, quando da aprovação de políticas para formação de agência e gestão de água dos rios. Na legislação brasileira da década de 1990, Bacia Hidrográfica também se torna um conceito de gestão de recursos hídricos. Foi no contexto da redemocratização do Brasil, da efervescência dos movimentos sociais, entre eles os ambientais, bem como do contexto mundial em que se avançavam os estudos e "debates acerca dos limites da intervenção humana na natureza" (Porto-Gonçalves, 2012, p.22) e da necessidade de repensar as relações humanas com estes recursos, que a Constituição Federal de 1988 garantiu a descentralização da gestão dos recursos hídricos e prevê a bacia hidrográfica como unidade administrativa que deveria constituir colegiados como instâncias decisórias para regular os usos pelos humanos dos recursos naturais incluídos ao território da bacia.

Anterior a 1988, no Brasil, a legislação sobre águas regulamentava e direcionava o uso da água para atender o setor econômico (atividades agrícolas, navegação e produção de energia hidrelétrica). Não se pensava a partir de conceitos de preservação e sustentabilidade ambiental. Na década de 1980, o contexto ambiental global, movimentado pelas demandas da chamada Era da Ecologia, influenciou e fomentou inúmeros eventos coletivos com a participação de pesquisadores, políticos, ambientalistas, entre outros, com o propósito de formular uma política nacional dos recursos hídricos. De acordo com Rajão et al. (2021, p.33):

movimentos ambientais começaram a estabelecer alianças entre si e, em 1986, formalizaram a Coordenação Interestadual Ecológica para a Assembleia Constituinte[...] Diante de um regime militar aberto para discutir questões ambientais e com as alianças se formando entre cientistas, políticos e movimentos ambientais, o tema ambiental tornou-se um dos mais centrais durante o processo de redemocratização.

Quase uma década depois, a Lei Federal n 9.433/1997, conhecida como a "Lei das Águas" é o ato regulatório advindo da constituição federal e dentre as inúmeras prerrogativas desta lei, estava a descentralização da gestão dos recursos hídricos delegada aos estados. Instituiu o Sistema Nacional de Gerenciamento dos Recursos Hídricos (SNGRH) e tornou-se uma lei disciplinadora, com a finalidade de promover a sustentabilidade hídrica do país. 
No Paraná, é a Lei no 12.726/1999 que regulamentou a Política Estadual de Recursos Hídricos. Ela é composta por fundamentos, objetivos, diretrizes e instrumentos de gestão. Organização que acompanha o previsto na legislação e política federal. Merece destaque as fases de implementação dos instrumentos de gestão, que segundo o Relatório de Conjuntura dos Recursos Hídricos do Estado do Paraná (2020) encontram-se em processo de elaboração e não efetivados.

Dentre as dezesseis bacias hidrográficas do Paraná, está a do rio Ivaí (IFigura 1), integralmente inserida no território paranaense, com duas unidades hidrográficas de gerenciamento de recursos hídricos: Baixo Ivaí e Alto Ivaí. Por questões de delimitação geográfica do território e sua relação com o curso do rio Ivaí propriamente, optou-se, nesta pesquisa, por apropriarse da definição geográfica de Parolin et al. (2010), que a subdividiram em Alto curso, Médio curso e Baixo curso (Figura 1), por compreenderem que ela apresenta diferentes características morfométricas, diferentes ambientes naturais e diferentes processos produtivos de ocupação e usos antrópicos.

Figura 1 - Bacia Hidrográfica do Rio Ivaí.

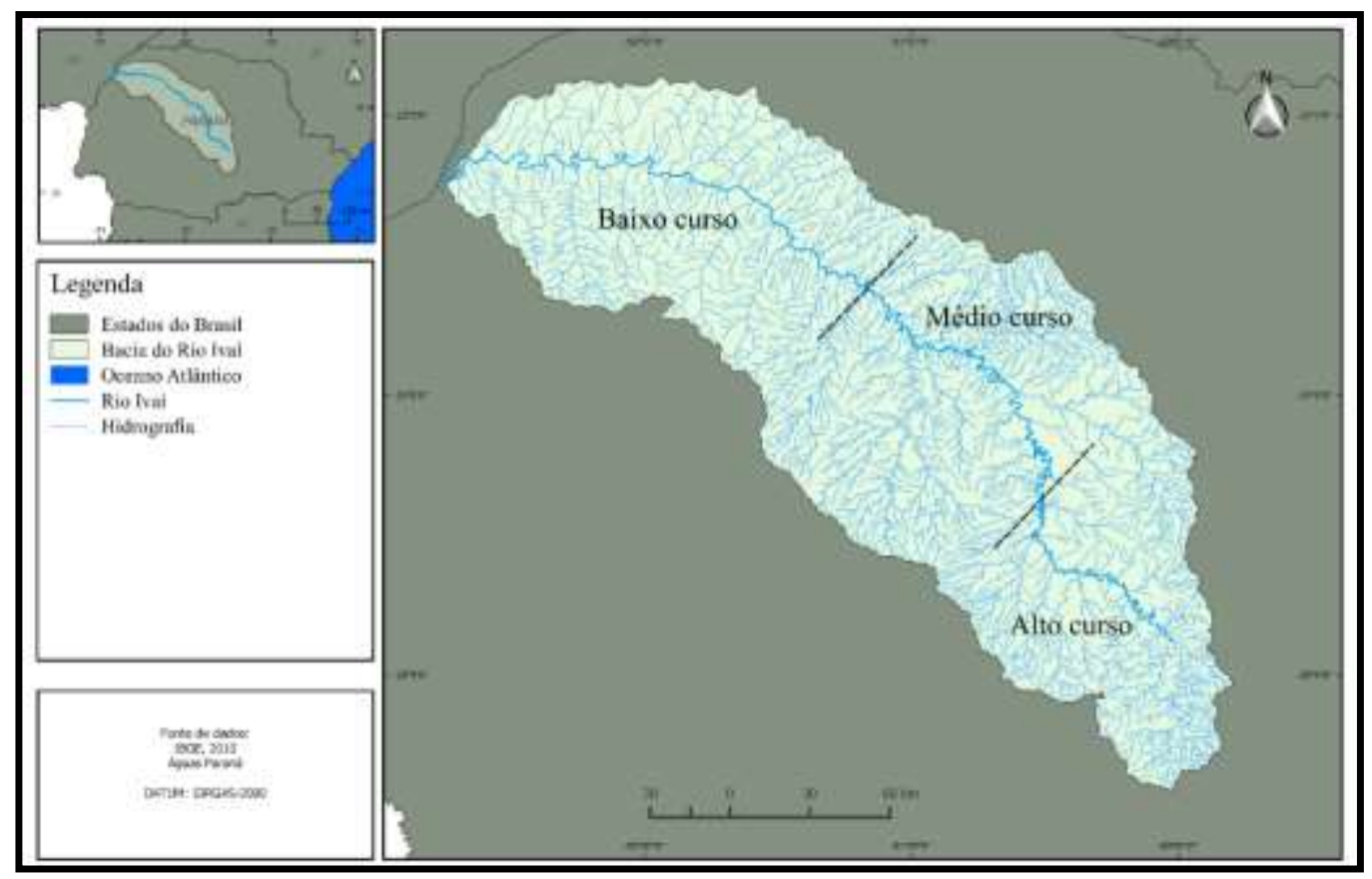

Fonte: Quiezi (2020, p. 33).

Para cada uma das Unidades de Gerenciamento de Recursos Hídricos, a Política Estadual de Recursos Hídricos prevê a constituição dos Comitês de Bacias, os quais são fóruns compostos por representantes do governo, representantes dos usuários e representantes da sociedade civil e destinam-se a discutir e propor atos regulatórios de "interesses comuns relacionados aos usos da água em uma bacia hidrográfica específica” (Paraná/IAT, 2020, p. 112).

Ao analisar as informações contidas na Figura 2, observa-se uma significativa lacuna entre o que prevê a Política Estadual de Recursos Hídricos e os estágios da implementação dos instrumentos de gestão previstos por Comitê de Bacia. No caso específico da Bacia Hidrográfica do Rio Ivaí, subdividida em dois comitês, ressalta-se o Baixo Ivaí em fase de análise quanto ao plano, o enquadramento e a cobrança do uso da água. Já o Alto Ivaí, no qual está inserido o médio curso, os instrumentos de gestão, mais de vinte anos após a Lei Estadual n 12.726/1999, ainda não existem. O que permite indagar por que deste ausente processo regulatório? Quais interesses entravam a efetiva implementação da Lei Estadual nº12.726/1999? Os distintos grupos sociais que atualmente ocupam a Bacia Hidrográfica do Rio Ivaí, podem ou não estar interferindo? 
Figura 2 - Estágios de Implementação dos Instrumentos de Gestão de Recursos Hídricos no Paraná por Comitê de Bacia Hidrográfica

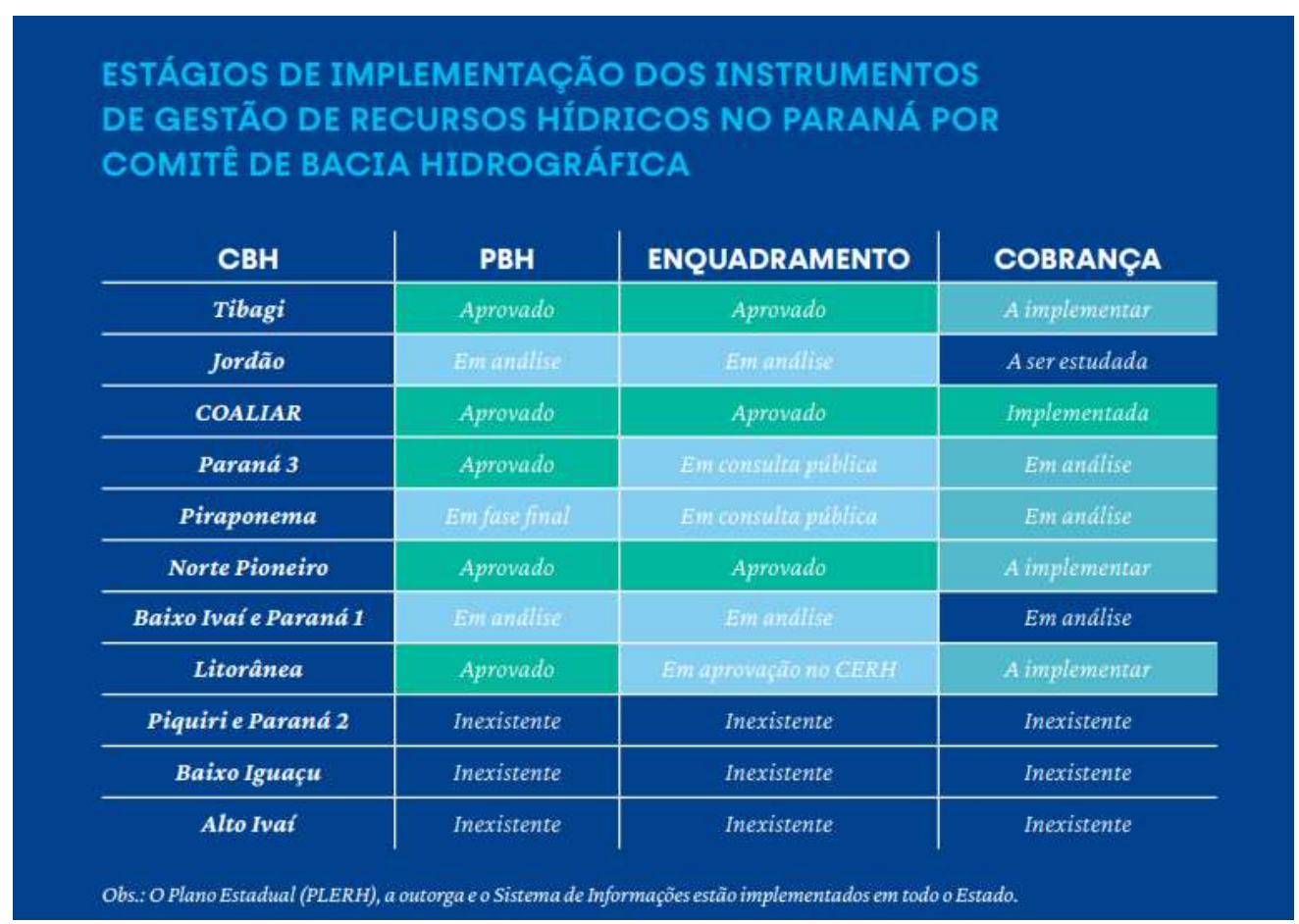

Fonte: Paraná/IAT (2020, p.119).

Diante da contextualização deste cenário regulatório, fez-se necessário recorrer ao trabalho de campo, para analisar as formas de apropriação e as práticas de alguns grupos sociais presentes às margens do rio Ivaí, os quais se constituíram em simultâneo ao processo de construção dos atos regulatórios, sendo, portanto, movidos e/ou influenciados pelo contexto externo. Por que não, também, movedores e influenciadores do atual estágio em que se encontra a organização e a gestão do Comitê de Bacia do Alto Ivaí?

O foco deste trabalho são os grupos sociais que atualmente ocupam e se apropriam do médio rio Ivaí, neste contexto de formulação e implementação dos instrumentos de gestão dos recursos hídricos, em decorrência dos atos regulatórios federal e estadual. Importante destacar que para se produzir uma história ambiental da Bacia Hidrográfica do Rio Ivaí seria necessário analisá-la a partir de suas relações humanas e não humanas ao longo do tempo, estabelecendo suas "temporalidades, permanências e transformações” (Arruda, 2015, p.217). Uma história em fase de produção. Entretanto e especificamente, o cenário atual no entorno do médio rio Ivaí constitui-se de distintos grupos sociais, entre eles: os pescadores ribeirinhos do Distrito de Porto Ubá e os proprietários de terras lindeiras (chacareiros, agricultores e pecuaristas). Cada um destes grupos sociais, possuem distintos interesses de uso do rio e/ou das terras às suas margens. Todos originários do processo de ocupação privada das terras a partir da década de 1950 .

\subsection{Os pescadores ribeirinhos de Porto Ubá}

A trajetória dos pescadores ribeirinhos de Porto Ubá, no município de Lidianópolis-Pr, foi recentemente analisada por Quiezi e Arruda (2021). Estes autores, evidenciaram que a trajetória dos pescadores deve ser compreendida a partir de três fases distintas: 
a primeira fase informal, não legalizada e não reconhecida (1930-1980); a segunda, quando a pesca foi regulamentada no rio e os pescadores se tornaram profissionais (1980-2000); a última fase, quando a pesca foi proibida e os pescadores se reinventaram, criando a Patrulha Ambiental do Rio Ivaí (2000-2020) (Quiezi \& Arruda, 2021, p.25).

Analisa-se que o percurso de atuação, profissionalização e institucionalização dos pescadores está relacionado com a dinâmica nacional de construção de políticas públicas, tanto para o setor da pesca, como para a gestão dos recursos hídricos. Dinâmica que foi fortemente influenciada pelo contexto internacional e nacional da efervescência dos movimentos sociais ambientais e da história ambiental como campo historiográfico.

$\mathrm{Na}$ fase atual, correspondente as duas primeiras décadas do século XXI, os pescadores, além de manterem seus registros profissionais e a institucionalidade por meio da Colônia de Pescadores de Porto Ubá Z-17 (Figura 3), reinventaram-se ao criar a Patrulha Ambiental do Rio Ivaí (P-A-R-I), como estratégia para comporem os espaços de discussão em relação aos usos e regulamentação da Bacia Hidrográfica do Rio Ivaí. Vale ressaltar que estes processos regulatórios são também advindos do contexto global da chamada Era da Ecologia.

Figura 3 - Colônias de Pescadores no Paraná.

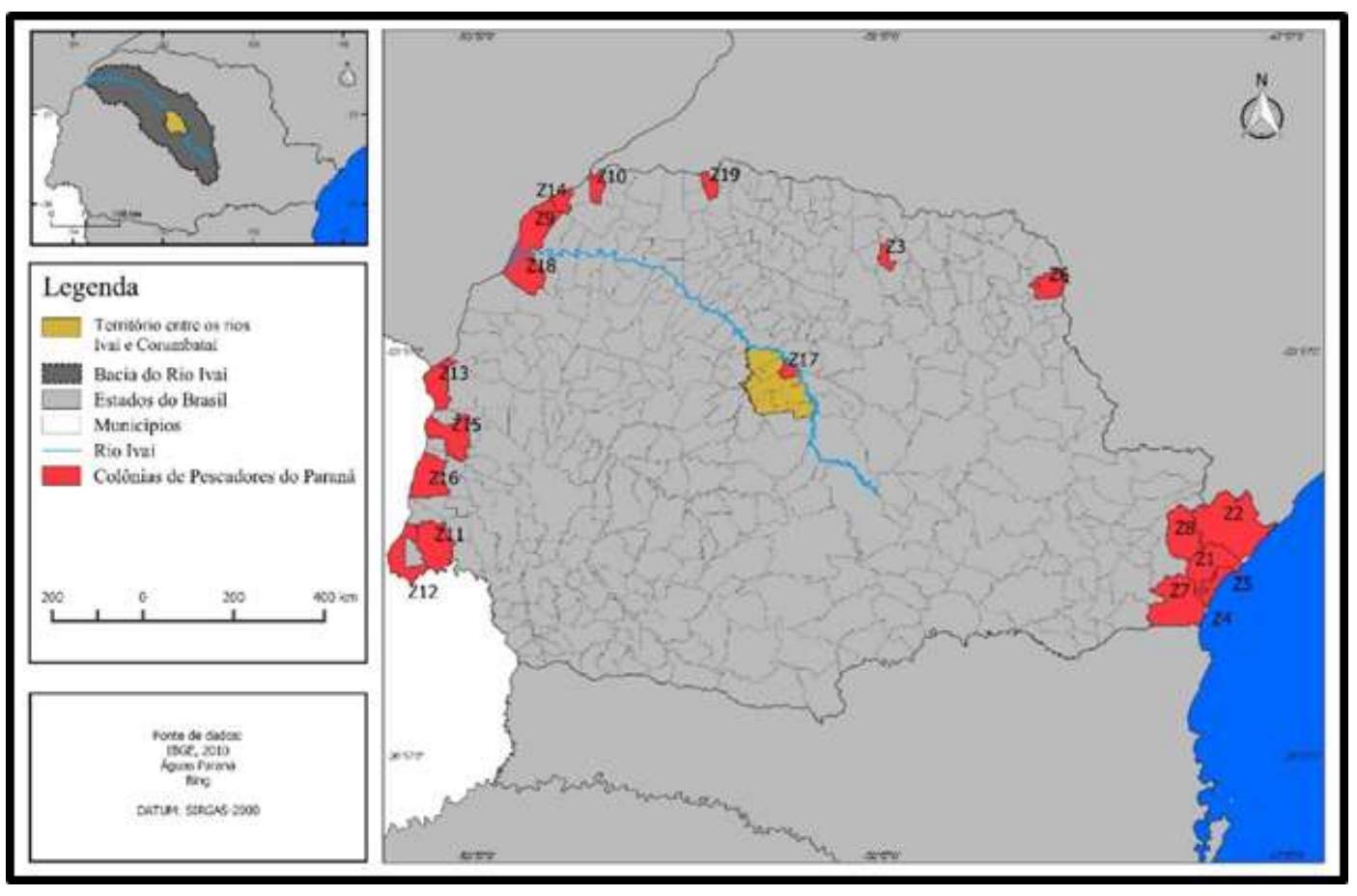

Fonte: Quiezi (2020, p. 183).

Fruto desta reinvenção e da consequente participação nos espaços de discussão que visam a regulamentação dos usos da água no rio Ivaí, os pescadores conseguiram a autorização de pesca profissional especificamente para o trecho do rio denominado de médio Ivaí. O ato regulatório é a Portaria do IAP n 135/2018 (Figura 4), a qual estabelece regras, normas e locais para o exercício profissional da pesca pelos pescadores ribeirinhos de Porto Ubá e/ou os filiados da Colônia de Pescadores Z-17. No Comitê de Bacia do Alto Ivaí, os pescadores compõem a representação da sociedade civil. 
Figura 4 - Locais de pesca proibida no rio Ivaí (2018).

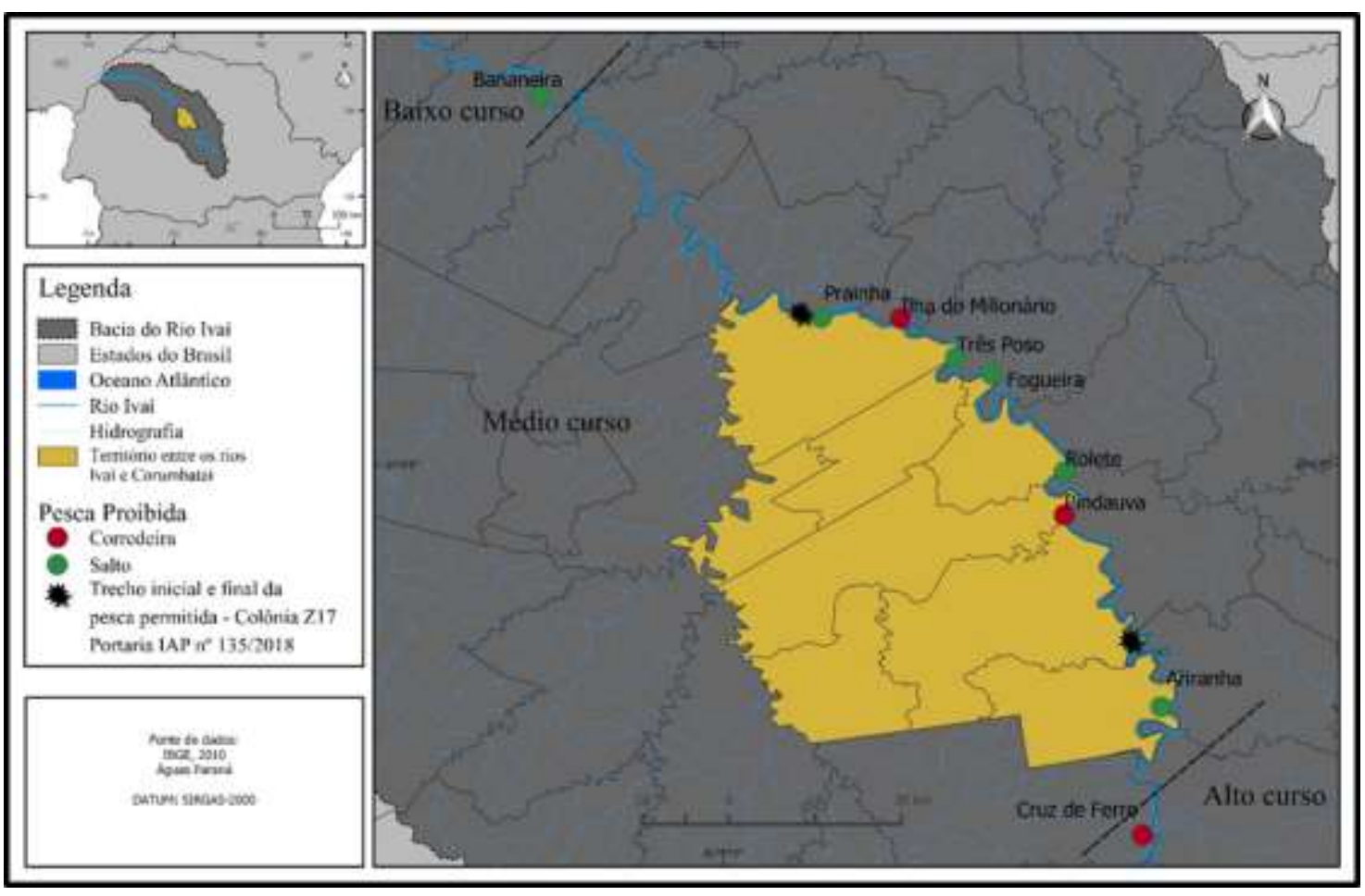

Fonte: Quiezi (2020, p. 196).

Contudo, as pesquisas de campo deste trabalho, revelaram um cenário antes não abordado pelos pescadores, que é dificuldade de acesso ao rio para o exercício da atividade da pesca. De acordo com alguns pescadores de Porto Ubá, para praticarem sua atividade profissional, faz-se necessário acessar o rio por caminho localizado abaixo da ponte, no Distrito de Porto Ubá e seguir de barco, a montante ou a jusante do rio, para os pontos liberados de pesca. Ou então, manter relação de amizade com alguns proprietários rurais lindeiros, o que nem todos conseguem, a fins de obter a autorização e/ou cópia das chaves de cadeados das porteiras para acessar o rio via estas propriedades.

\subsection{Os proprietários de terras lindeiras}

As terras localizadas às margens esquerda e direita de toda a Bacia Hidrográfica do Rio Ivaí, majoritariamente foram privatizadas e pertencem a uma diversidade de atores sociais que as ocupam e as usam praticando, especialmente no caso do médio Ivaí, a agricultura familiar, o plantio monocultor (soja, trigo, milho e cana), a criação de gado leiteiro e de corte, a construção de empreendimentos imobiliários a fins de loteamento para lazer às margens do rio e chácaras particulares, também para descanso e lazer. No Comitê de Bacia do Alto Ivaí, estes ocupam vaga na representação dos usuários.

A legalidade quanto a essas formas de ocupação privada, demandaria análise de atos regulatórios específicos como o Código Florestal Brasileiro e a legislação fundiária rural. Pesquisa em andamento, mas que não caberá análise aqui. Portanto, parte-se do pressuposto que as terras localizadas às margens do médio rio Ivaí, são de domínio particular e privado, salvo a terra do atual Parque Estadual de Vila Rica do Espírito Santo (PEVRES) (Decreto Estadual no 3279 de 18 de novembro de 2011), que é uma unidade de conservação estadual, devido ao seu valor histórico, arqueológico e biodiversidade. Neste local, estão as ruínas de Villa Rica del Espiritu Santu, comunidade espanhola do século XVI.

Já o rio Ivaí, de acordo com a Constituição Federal de 1988 artigo 26, é de dominialidade do Estado do Paraná (Figura 5). Dominialidade aqui compreendida, tomando o artigo 225 da Constituição, como "bem de uso comum do povo", que perpassa a condição de pertencimento a uma pessoa física ou jurídica de cunho privado ou público. Neste caso, a dominialidade dos 
recursos hídricos está para a gestão e o gerenciamento coletivo por aqueles que nutrem interesses de uso, regulamentado e com instrumentos de gestão em fase de elaboração e implementação, conforme Relatório de Conjuntura dos Recursos Hídricos do Estado do Paraná (2020).

Figura 5 - Dominialidade do rio Ivaí - Paraná.

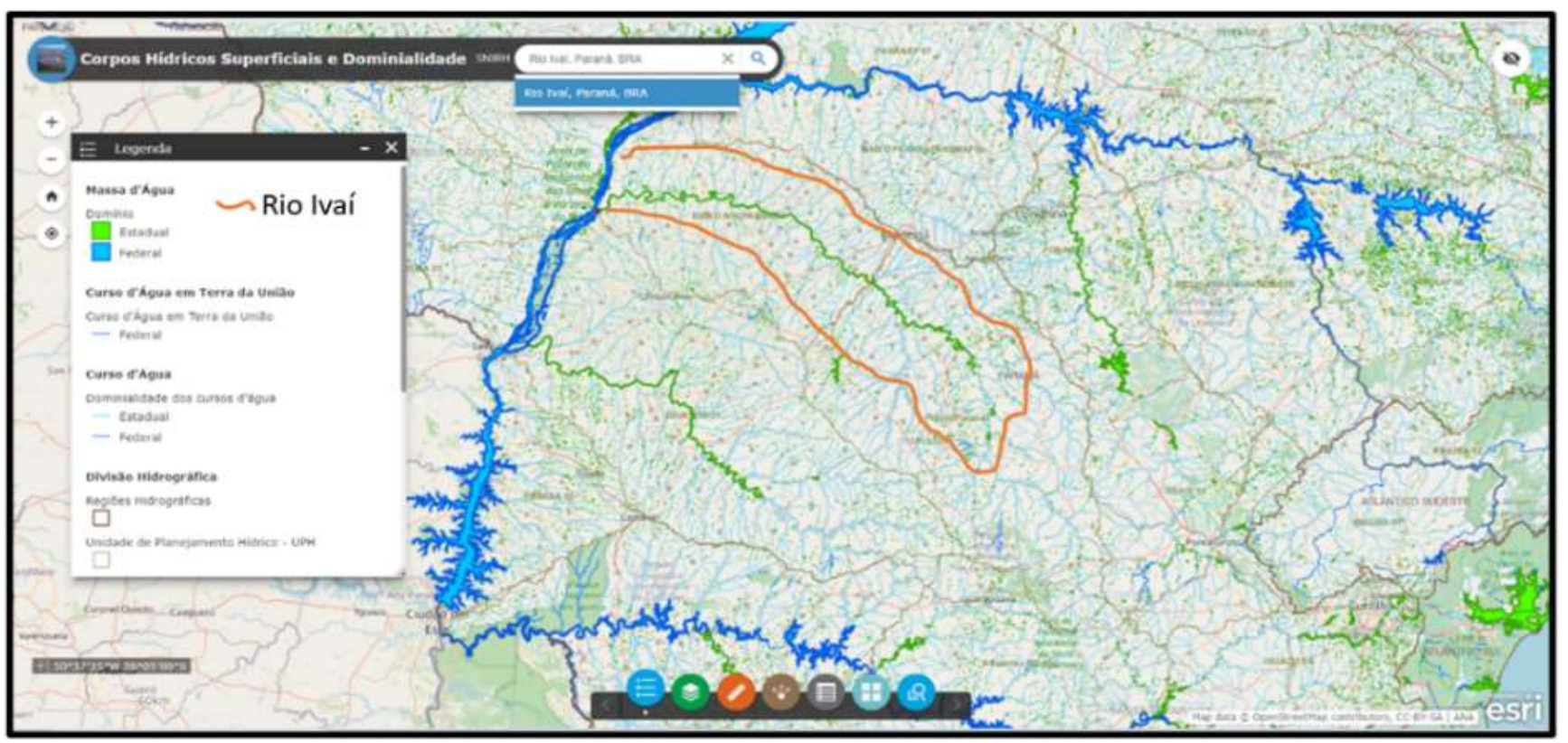

Fonte: Brasil/SNIRH (2021), Organizado por: Quiezi (2021).

Neste sentido, recuperando as informações dos estágios de implementação dos instrumentos de gestão de recursos hídricos no Paraná por Comitê de Bacia Hidrográfica (Figura 1), no qual o Alto Ivaí aparece com um quadro de inexistência de todos os seus instrumentos, à campo evidencia-se um processo de apropriação privada, no qual os proprietários, ao restringir o acesso às suas terras, também restringe o acesso ao rio (Figuras 6 a 10).

Ao percorrer pelo território do médio Ivaí é muito comum encontrar paisagens ocupadas, cercadas e com acesso restrito diante das inúmeras porteiras com cadeados. Paisagens que produzem inúmeros questionamentos quanto as relações que estes grupos sociais mantêm entre si e com a natureza.

Figura 6 - Porteira de acesso à propriedade particular.

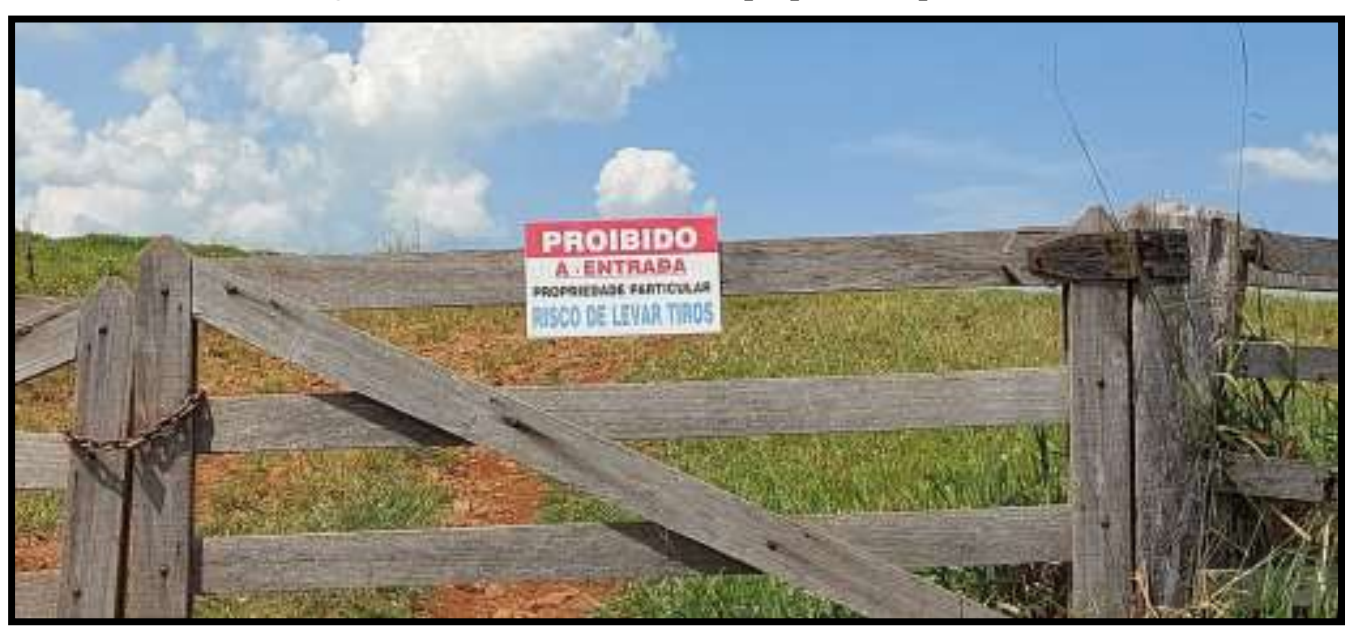

Foto: Quiezi (2020). 
Research, Society and Development, v. 10, n. 14, e464101420522, 2021

(CC BY 4.0) | ISSN 2525-3409 | DOI: http://dx.doi.org/10.33448/rsd-v10i14.20522

Figura 7 - Portão de acesso ao rio Ivaí de um empreendimento imobiliário particular.

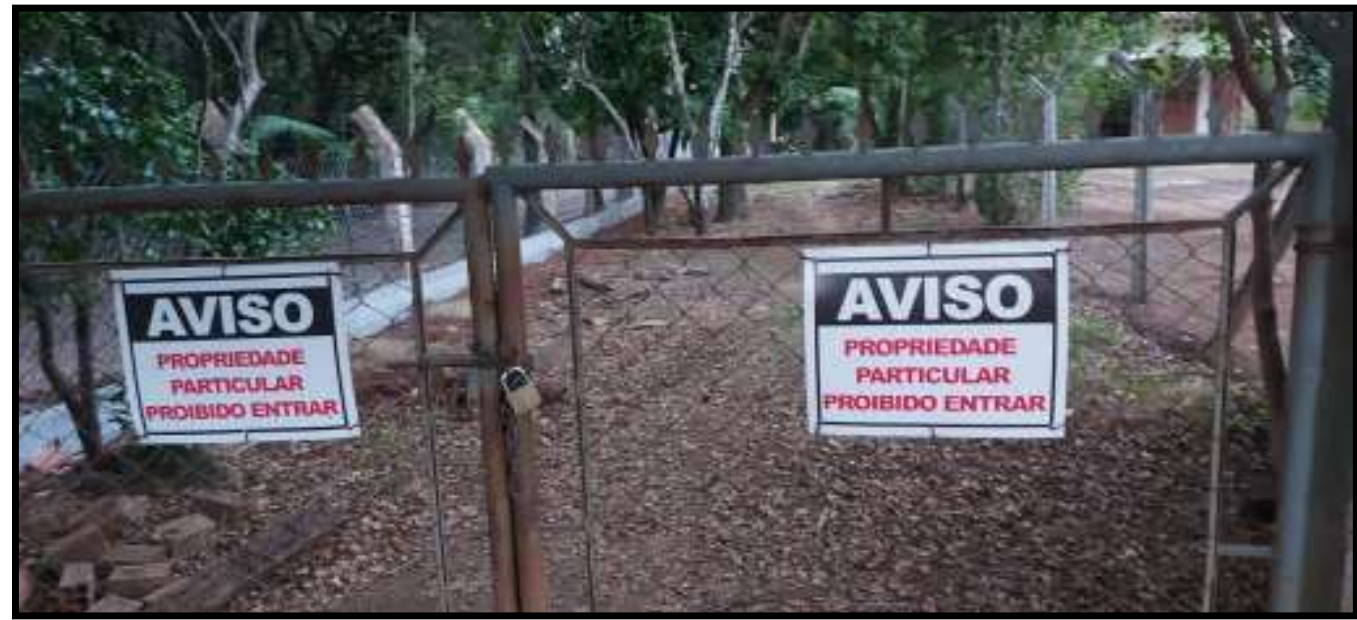

Foto: Quiezi (2020).

Figura 8 - Desmatamento para o plantio de monoculturas.

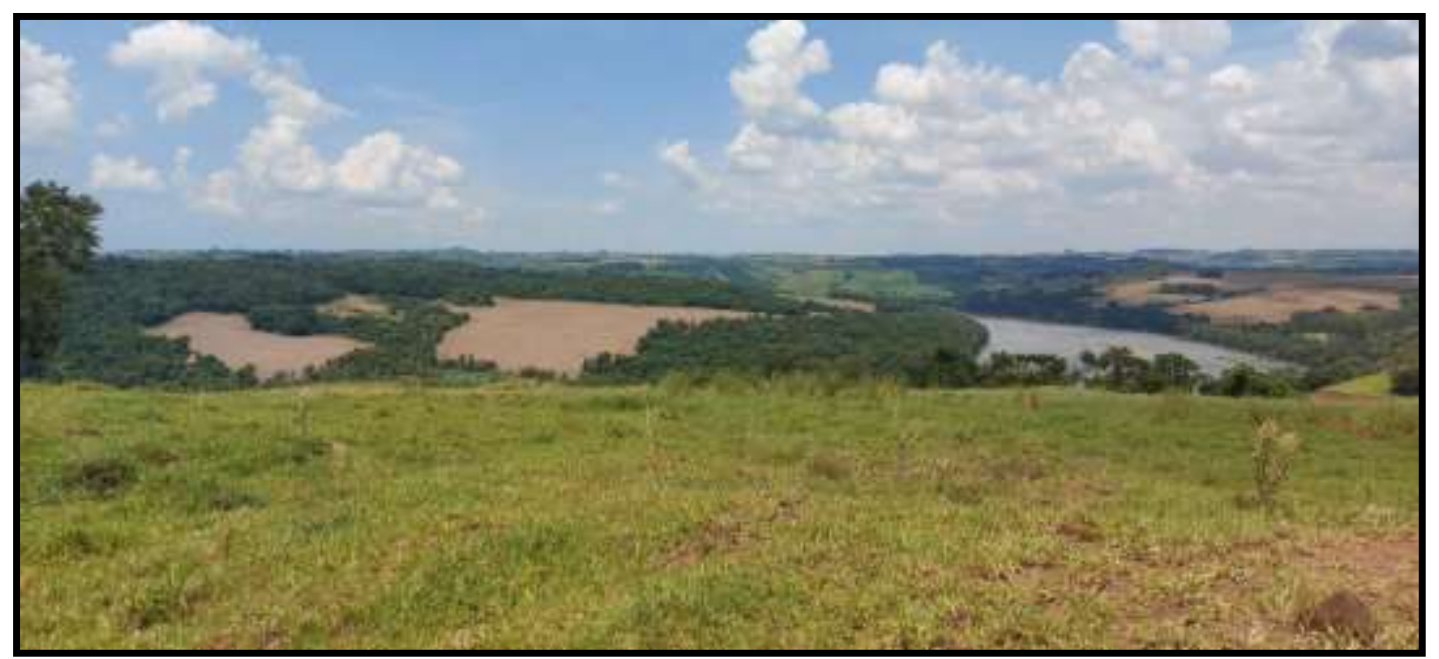

Foto: Quiezi (2020).

Neste momento, não se tem o propósito de analisar a legalidade ou não das formas de apropriação das terras às margens do médio Ivaí (Figuras 6 a 9). O estágio ainda é de levantamento de fontes e do exercício de problematizar ao verificar as lacunas entre o que estabelece os atos regulatórios com o que de fato ocorre na prática, quanto aos processos implementação dos instrumentos de gestão dos recursos hídricos, de apropriação e da ocupação das terras, que podem estar impactando a dinâmica natural do rio e o acesso a ele por parte dos pescadores filiados à Colônia de Pescadores de Porto Ubá Z-17, os quais dependem deste acesso para exercerem a atividade profissional da pesca. 
Research, Society and Development, v. 10, n. 14, e464101420522, 2021

(CC BY 4.0) | ISSN 2525-3409 | DOI: http://dx.doi.org/10.33448/rsd-v10i14.20522

Figura 9 - Apropriação particular de Ilha no médio Ivaí.

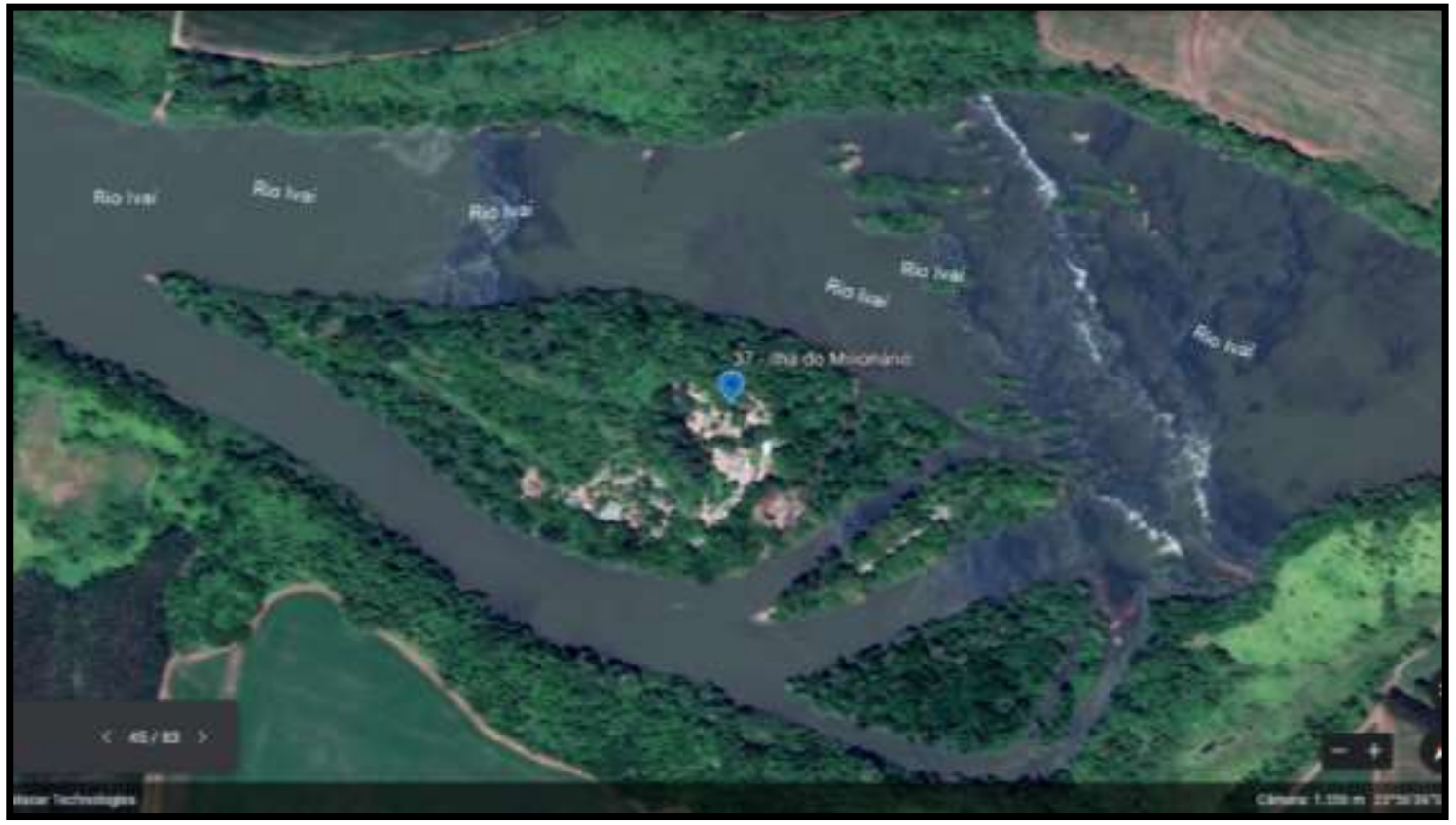

Fonte: Google Earth (2020). Organizado por: Quiezi (2020).

Figura 10 - Ocupação do solo para criação de gado.

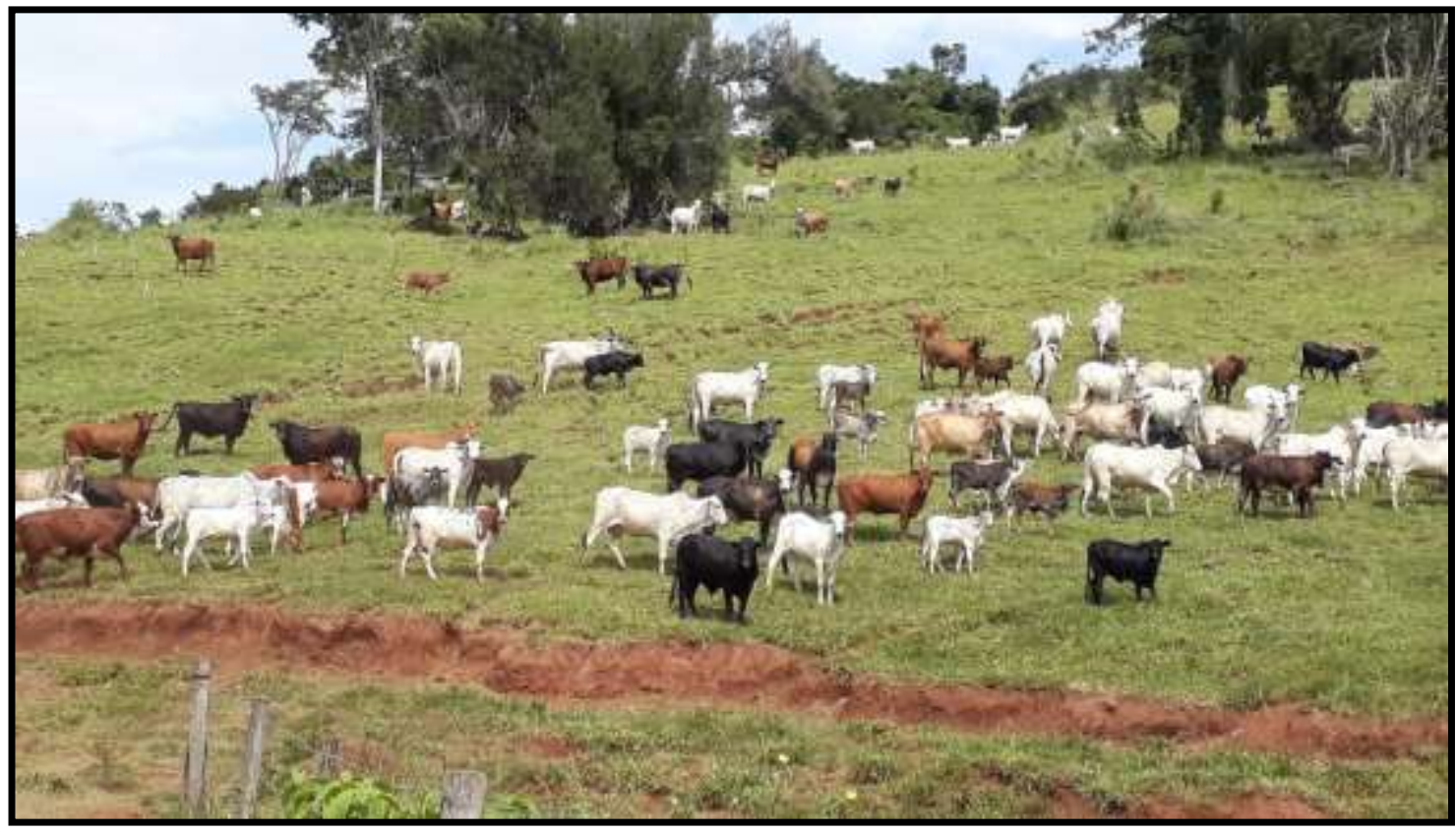

Foto: Quiezi (2020).

O atual cenário de apropriações sociais da natureza (Figuras 3 a 7), revelam a presença de diferentes grupos humanos, com distintos interesses de usos das terras e do rio Ivaí, no seu médio curso. São grupos que possuem posições divergentes e, portanto, em disputas. Particularidades e relações, sobretudo de poder, que neste momento, podem estar influenciando o atual estágio de estagnação das ações necessárias para a implementação dos instrumentos de gestão via Comitê de Bacia do Alto Ivaí. Carvalho (2017, p. 51), contribui com esta análise ao afirmar que: 
mais que um confronto do ser humano com a natureza o que se tem é um confronto entre seres humanos. Em geral o que se tem é uma disputa de diferentes formas de apropriação e gestão daquele ecossistema. Uma disputa para ver quem terá ou não acesso aos recursos e a que forma de acesso terão.

E o Estado, também de acordo com Carvalho (2017, p. 51), enquanto "regulador dos conflitos sociais" não consegue gerenciar ações "unívoca" por também ser um "campo de conflitos" no que tange a sua à composição e, consequentemente, suas ações.

O comitê pode estar sendo ocupado por representantes de grupos sociais que de fato o querem manter neste estágio lento ou inexistente de atuação efetiva. Interessante pontuar que, enquanto os proprietários lindeiros se fazem representar no Comitê como usuários, os pescadores ocupam vaga na representação da sociedade civil. Isto porque, reinventaram-se por meio da Patrulha Ambiental do Rio Ivaí, estrategicamente para inserirem-se nestes espaços. Entretanto, como pescadores profissionais, não deixaram de ser também usuários. Seja como patrulheiros ou pescadores, também estão em disputa pelo rio.

Proposto pela Resolução nº78 de dezembro de 2012 do Conselho Estadual de Recursos Hídricos do Paraná (CERH/PR), o Comitê da Bacia do Alto Ivaí foi instituído por meio do decreto estadual nº8859 em setembro de 2013 . Em maio de 2012, o CERH/PR com vista a implementação do comitê, elaborou uma descrição suscinta das características do Alto Ivaí. Conforme demonstra o Quadro 1, somente em 2020 o comitê como instância deliberativa, retoma as atividades, ainda que de forma bastante lenta.

Quadro 1 - Comitê de Bacia do Alto Ivaí.

\begin{tabular}{|c|c|c|}
\hline Ato regulatório & Descrição & Esfera/institucional \\
\hline Constituição Federal de 1988 & $\begin{array}{l}\text { Art. } 26 \text { e } 255 \text { - descentralização de gestão dos recursos } \\
\text { hídricos e dominialidade das águas. }\end{array}$ & Federal \\
\hline $\begin{array}{l}\text { Lei Federal n } 9.433 \text { de } 08 \text { de janeiro } \\
\text { de } 1997\end{array}$ & $\begin{array}{l}\text { Política Nacional dos Recursos Hídricos e a bacia } \\
\text { hidrográfica como instrumento de gestão (planejamento e } \\
\text { gerenciamento) }\end{array}$ & Federal \\
\hline $\begin{array}{l}\text { Lei Estadual } \mathrm{n}^{\circ} 12.726 \text { de } 26 \text { de } \\
\text { novembro de } 1999\end{array}$ & $\begin{array}{l}\text { Política Estadual de Recursos Hídricos e a bacia } \\
\text { hidrográfica como instrumento de gestão (planejamento e } \\
\text { gerenciamento) }\end{array}$ & Estadual \\
\hline Maio/2012 & $\begin{array}{l}\text { Descrição e diagnóstico da unidade hidrográfica do Alto } \\
\text { Ivaí com vistas à criação do Comitê de Bacia }\end{array}$ & $\begin{array}{l}\text { Conselho Estadual de Recursos } \\
\text { Hídricos do Paraná }\end{array}$ \\
\hline $\begin{array}{l}\text { Resolução nº78 de dezembro de } \\
2012\end{array}$ & Proposta de Implantação do Comitê da Bacia do Alto Ivaí & $\begin{array}{l}\text { Conselho Estadual de Recursos } \\
\text { Hídricos do Paraná }\end{array}$ \\
\hline $\begin{array}{l}\text { Decreto Estadual no } 8859 \text { de } 04 \text { de } \\
\text { setembro de } 2013\end{array}$ & $\begin{array}{l}\text { Institui o Comitê da Bacia do Alto Ivaí e nomeia seus } \\
\text { representantes. }\end{array}$ & Estadual \\
\hline $1^{\circ}$ de setembro de 2020 & $\begin{array}{l}\text { Constituição em reunião extraordinária da nova diretoria } \\
\text { do Comitê de Bacia Alto Ivaí (mandato 2020/2024) }\end{array}$ & Comitê de Bacia Alto Ivaí \\
\hline $\begin{array}{l}\text { Deliberação } n^{\circ} 01 \text { de } 07 \text { de julho de } \\
2021\end{array}$ & $\begin{array}{l}\text { Cria a Câmara Técnica de Instrumentos de Gestão do } \\
\text { Comitê da Bacia do Alto Ivaí - CTINS }\end{array}$ & Comitê de Bacia Alto Ivaí \\
\hline
\end{tabular}

Fonte: Organizado por Quiezi (2020).

De acordo com o Relatório de Conjuntura dos Recursos Hídricos do Estado do Paraná (2020), é evidente o descompasso entre a legislação em vigor e a constituição, regulamentação e atuação dos comitês de bacia enquanto parte dos instrumentos de gestão dos usos dos recursos hídricos. Entretanto, salta aos olhos o estágio de "inexistência" em que se encontra o Comitê de Bacia do Alto Ivaí, que em 2021 ainda vivencia o desafio da construção do diagnóstico e da elaboração do plano de bacia hidrográfica (Figura 1).

Dentre a composição atual dos membros do Comitê de Bacia do Alto Ivaí, destaca-se os usuários representados por empresas do setor de captação de água, serviços de esgoto, setor energético, usina de cana-de-açúcar, ramo agropecuário, 
empreendimentos turísticos. Já a sociedade civil, faz-se representar destacadamente pela presença do ensino e pesquisa (universidades), mas também pela "agenda 21 de Campo Mourão", os pescadores, a terra indígena, a OAB e o CREA.

Analisando o histórico de constituição do Comitê de Bacia do Alto Ivaí (Quadro 1) e fundamentando-se no trabalho a campo, conclui-se que o próprio processo, lacunar e em descompasso com a legislação nacional e estadual, revela os conflitos e disputas, não só para ocupar os espaços de representatividade, mas também as estratégias de estagnar e/ou inibir uma efetiva atuação do comitê. Pode-se afirmar que os grupos sociais que na prática apropriaram-se das terras e do rio, disputam pela legitimação do direito de uso nos espaços deliberativos de atos regulatórios, utilizando-se inclusive das relações de poder político e econômico para neutralizar as ações do próprio espaço deliberativo.

\section{Considerações Finais}

Fundamentando-se em Drummond (2002), o Brasil se apresenta como um território para os estudos da história ambiental. E, portanto, a Bacia Hidrográfica, pode ser considerada um recorte geográfico, uma unidade espacial, conforme analisaram Pádua (2010) e Arruda (2015). Dentre as possibilidades metodológicas, utilizou do trabalho de campo (Drummond, 1991).

Analisou-se que a Constituição Federal de 1988, constituiu-se como marco regulatório para a gestão dos recursos hídricos de forma sustentável e descentralizada. Fruto de um processo anterior, das décadas de 1970 e 1980 , quando da efervescência de movimentos sociais ambientais internacional e nacional, analisados por Rajão et al. (2021) e da origem do campo historiográfico da história ambiental, cujas preocupações centrais pautavam-se em repensar os usos, as ações e as relações do humano com a natureza. Um movimento mundialmente conhecido como a Era da Ecologia.

Diante da necessidade de regulamentação do que preconizou a Constituição Federal no âmbito da gestão dos recursos hídricos, elaborou-se e aprovou-se a Lei Federal no 9.433/1997, conhecida como "Lei das Águas". Ela Instituiu a Política Nacional de Recursos Hídricos e criou o Sistema Nacional de Gerenciamento de Recursos Hídricos. No Paraná, a Política Estadual de Recursos Hídricos foi instituída pela Lei n ${ }^{\circ}$ 12.726/1999. Cujo destaque aqui deu-se para o descompasso e atrasos em relação as fases de implementação dos instrumentos de gestão, conforme avaliado pelo Relatório de Conjuntura dos Recursos Hídricos do Estado do Paraná (2020).

Na sequência, apresentou-se a Bacia Hidrográfica do Rio Ivaí (mapa 1 e 2), com a evidência da "inexistência” (Figura 1) dos instrumentos de gestão a serem implementados pelo Comitê de Bacia do Alto Ivaí. E a partir do "trabalho de campo" (DRUMMOND, 1999) destacou-se algumas das formas de apropriação privada das terras localizadas as margens do rio Ivaí (Figuras 3 a 7), cujas práticas e usos, podem estar restringindo o acesso ao rio Ivaí, sobretudo dos pescadores filiados a Colônia de Pescadores de Porto Ubá Z-17. Um cenário que, analisado também a partir do histórico de composição e implantação do Comitê de Bacia do Alto Ivaí, revelou os conflitos sociais e as disputas por usos do rio, ao considerar o conceito de dominialidade dos recursos hídricos, compreendido como a gestão de uso comum das águas (CF/1988).

Os pescadores e os proprietários de terras lindeiras, foram compreendidos e analisados como grupos sociais distintos, os quais disputam por usos e acesso ao rio Ivaí. É preciso postular outros elementos teóricos e conceituais, reunir outras fontes (documentais, orais e de observação) para aprofundar a análise das problematizações preliminares deste trabalho. Contudo, evidencia-se um cenário em constante disputa, cujos atores apropriam-se de diversas estratégias, dentre elas: a ocupação e estagnação da atuação da instância deliberativa (o comitê); as porteiras, os cadeados e as placas que sinalizam a posse privada da terra e, consequentemente do acesso ao rio; a institucionalização e reinvenção dos pescadores com vistas a se fazerem representar; a dinâmica de ocupação e usos das terras que, a mercê da legislação, restringe o acesso ao rio e impacta a paisagem, já claramente marcada e transformada. 
Este trabalho compõem as pesquisas em nível de doutorado de uma das autoras, a qual pretende analisar a história ambiental do rio Ivaí, as demandas que emergiram após a década de 1970 e as particularidades que podem estar influenciando as relações dos humanos com a natureza, configurando-se em um cenário de disputa pelo rio.

\section{Referências}

Acselrad, H. (2002). Justiça Ambiental e construção social do risco. DMA - Desenvolvimento e Meio Ambiente. 5, 49-60. Editora UFPR. https://revistas.ufpr.br/made/article/view/22116/14480

Alier, J. M. (1997). O ecologismo dos pobres. Raega - O Espaço Geográfico em Análise. 1, https://revistas.ufpr.br/raega/article/view/17910/11685. http://dx.doi.org/10.5380/raega.v1i0.17910.

Arruda. G. (2015). Bacias hidrográficas, história ambiental e temporalidades. Revista de História Regional. 20(2), 209-31. http://www.revistas2.uepg.br/index.php/rhr.

Brasil. (1988). Constituição da República Federativa do Brasil. http://www.planalto.gov.br/ccivil_03/constituicao/constituicao.html

Brasil. (1997). Lei $n^{\circ}$ 9.433, de 8 de janeiro. Institui a Política Nacional de Recursos Hídricos, cria o Sistema Nacional de Gerenciamento de Recursos Hídricos, regulamenta o inciso XIX do art. 21 da Constituição Federal, e altera o art. $1^{\circ}$ da Lei $n^{\circ} 8.001$, de 13 de março de 1990 , que modificou a Lei ${ }^{\circ} 7.990$, de 28 de dezembro de 1989. Brasília, D.F. http://www.planalto.gov.br/ccivil_03/leis/19433.htm

Brasil. (2021). Portal do Sistema Nacional de Informações sobre Recursos Hídricos (SNIRH). Corpos Hídricos Superficiais e Dominialidade. https://portal1.snirh.gov.br/ana/apps/webappviewer/index.html?id=ef7d29c2ac754e9890d7cdbb78cbaf2c.

Carvalho, E. B. (2017). Inspirar amor à terra. Uma história ambiental da colonização moderna no Brasil, o caso de Campo Mourão, Paraná, $1939-1964$. Alameda.

Carvalho, E. B. (2010). No fundo da mata virgem: a complexidade de um elemento mítico no imaginário ocidental sobre a natureza. Florianópolis, SC: Revista Tempo e Argumento, 2(2), 135 - 153. https://revistas.udesc.br/index.php/tempo/article/view/2175180302022010135

Drummond, J. A (1991) A história ambiental: temas, fontes e linhas de pesquisa. Revista Estudos Históricos, 4(8), 177-197. http://bibliotecadigital.fgv.br/ojs/index.php/reh/article/view/2319.

Drummond, J. A (2002). Por que estudar a história ambiental do Brasil? - ensaio temático. Revista Varia História, (26), 13-3. https://static1.squarespace.com/static/561937b1e4b0ae8c3b97a702/t/572b555f4c2f8564c3833c55/1462457695947/01_Drummond\%2C+Jose+Augusto.pdf

Ferri, G. K. (2021). História Ambiental: historiografia comprometida com a vida. In: Café História. https://www.cafehistoria.com.br/historia-ambientalhistoriografia-comprometida-com-a-vida/.

Leff, E. (2006). Racionalidade ambiental: a reprodução social da natureza. Tradução: Luis Carlos Cabral. Rio de Janeiro: Civilização Brasileira.

Pádua. J. A. (2010), José Augusto. As Bases Teóricas da História Ambiental. Estudos Avançados, 24(68), 81-101. http://www.scielo.br/scielo.php?script=sci_arttext\&pid=S0103-40142010000100009

Paraná. (1999). Lei Estadual $n^{\circ} 12.726$ de 26 de novembro. Institui a Política Estadual de Recursos Hídricos e adora outras providências. https://www.legislacao.pr.gov.br/legislacao/pesquisarAto.do?action=exibir\&codAto=5849

Paraná. (2018). Portaria IAP $n^{\circ}$ 135, 26 de junho. Portaria Gabinete. Paraná. http://celepar7.pr.gov.br/sia/atosnormativos/form_cons_ato1.asp?Codigo=3875

Paraná. (2013). Decreto 8859 de 04 de setembro. Institui o Comitê da Bacia do Alto Ivaí e nomeia seus representantes. https://www.legislacao.pr.gov.br/legislacao/pesquisarAto.do?action=exibir\&codAto=101267\&indice=1\&totalRegistros=1\&dt=22.2.2019.10.0.34.388

Paraná (2012). Resolução no 78 - CERH/PR, de 11 de dezembro. Aprova a proposta de instituição do Comitê da Bacia do Alto Ivaí e a proposição de composição de sua Mesa Diretora Provisória. Secretaria de Estado do Meio Ambiente e Recursos Hídricos. https://www.sedest.pr.gov.br/sites/default/arquivos_restritos/files/migrados/File/CERH_-_20_RO/resolucao_n_78_mdp_alto_ivai.pdf.

Paraná. (2011). Decreto Estadual $\mathrm{n}^{\circ} 3279$ de 18 de novembro. Cria o Parque Estadual de Vila Rica do Espírito Santo, no município de Fênix. https://www.legislacao.pr.gov.br/legislacao/pesquisarAto.do?action=exibir\&codAto=62176\&indice=1\&totalRegistros=7\&dt=1.8.2021.7.7.5.372

Paraná. (2021). Descrição e diagnóstico da Unidade Hidrográfica do Alto Ivaí com vistas à criação do Comitê de Bacia. Secretaria do Desenvolvimento Sustentável e do Turismo. https://www.sedest.pr.gov.br/sites/default/arquivos_restritos/files/migrados/File/CERH__20_RO/descricao_diagnostico_alto_ivai.pdf.

Paraná. (2021) Comitê de Bacia do Alto Ivaí. Instituto Água e Terra - IAT. http://www.iat.pr.gov.br/Pagina/Comite-da-Bacia-do-Alto-Ivai

Paraná. (2021) Conselho de Recursos Hídricos. Secretaria do Desenvolvimento Sustentável e do Turismo. https://www.sedest.pr.gov.br/CERH\#

Paraná. (2020). Relatório de conjuntura dos recursos hídricos do Estado do Paraná. Curitiba: IAT-Instituto Água e Terra. http://www.iat.pr.gov.br/sites/aguaterra/arquivos_restritos/files/documento/2020-07/relatorio_conjuntura_recursoshidricos_2020.pdf

Parolin, M., Volkmer-Ribeiro, C.; \& Leandrini, J. (Orgs). (2010). Abordagem ambiental interdisciplinar em bacias hidrográficas no Estado do Paraná. Campo Mourão: Editora da Facilcam, 2010. https://cutt.ly/Ya2A7m2 
Research, Society and Development, v. 10, n. 14, e464101420522, 2021

(CC BY 4.0) | ISSN 2525-3409 | DOI: http://dx.doi.org/10.33448/rsd-v10i14.20522

Porto-Gonçalves, C. W. (2012) A ecologia política na américa latina: reapropriação social da natureza e reinvenção dos territórios. Florianópolis (SC): Interthesis, 9(1). https://periodicos.ufsc.br/index.php/interthesis/article/view/1807-1384.2012v9n1p16/23002

Porto, M \& Porto, R. L. L. (2008). Gestão de bacias hidrográficas. Estud. av., 22(63), 43-60. https://www.scielo.br/j/ea/a/ccy h4cf7NMdbpJdhSzCRNtR/?lang=pt\&format=pdf

Quiezi, S. A. (2020) Pescadores, indígenas, posseiros e agricultores no médio rio Ivaí: trajetórias, conflitos e transformações da paisagem (1870-1960). 274 f. Dissertação (Mestrado em História) - Universidade Estadual de Maringá, Maringá.

Quiezi, S. A. (2020) \& Arruda, G. (2021). De balseiros a patrulheiros ambientais: as trajetórias dos pescadores de Porto Ubá no médio rio Ivaí-PR (1930-2020). Revista Faces da História: 8(1), 25-49, https://seer.assis.unesp.br/index.php/facesdahistoria/article/view/1959/1775

Rajão, R., Giudice, R., Hoff, R., \& Carvalho, E. B. (2021). Uma breve história da Legislação Florestal Brasileira. contém a Lei n 12.651, de 2012, com comentários críticos acerca da aplicação de seus artigos. Expressão.

Schama, S. (1996). Paisagem e Memória. Tradução: Hildegard Feist. Companhia das Letras. 